Short Communication

Animal Genetics

\title{
Cytogenetic analysis of three Ctenidae species (Araneae) from the Amazon
}

\author{
José Paulo da Costa Pinto Neto ${ }^{1}$ (D) , Leonardo Gusso Goll ${ }^{2}$ (D) , Maria Claudia Gross ${ }^{3}$ (D) , \\ Eliana Feldsberg ${ }^{1}\left(\mathbb{D}\right.$ and Carlos Henrique Schneider ${ }^{4}$ \\ ${ }^{1}$ Instituto Nacional de Pesquisas da Amazônia - INPA, Programa de Pós-graduação em Genética, \\ Conservação e Biologia Evolutiva, Manaus, AM, Brazil. \\ ${ }^{2}$ Instituto de Natureza e Cultura - INC, Benjamin Constant, AM, Brazil. \\ ${ }^{3}$ Universidade Federal da Integração Latino-Americana, Foz do Iguaçu, PR, Brazil. \\ ${ }^{4}$ Centro Universitário União Dinâmica das Cataratas, Foz do Iguaçu, PR, Brazil.
}

\begin{abstract}
Cytogenetic characterization was performed on three wandering spiders: Ctenus amphora Mello-Leitão, 1930, C. crulsi Mello-Leitão, 1930 and C. villasboasi Mello-Leitão, 1949. The three species had similar karyotypes, with $2 n=28$ (26 + $\mathrm{X}_{1} \mathrm{X}_{2} \mathrm{O}$ ) in males, with sex chromosomes exhibiting positive heteropicnosis in meiotic cells. 18S rDNA mapping revealed gene sites at the terminal region of one chromosomal pair for all species, with one $C$. crulsi individual, showing markings in two pairs. C. villasboasi showed markers only in the pachytene phase. The distribution pattern of constitutive heterochromatin was found to be characteristic for the genus, with markings in the centromeric region of all chromosomes, suggesting an acrocentric morphology for all chromosomes of the three analysed species. The results support the fusion of sex chromosomes as an evolutionary tendency for this spider group.
\end{abstract}

Keywords: Meiosis, FISH, NORs, spider, Amazon.

Received: March 10, 2020; Accepted: September 03, 2020.

The order Araneae currently contains 48,455 described species, distributed in 120 families (World Spider Catalog, 2020). In Brazil, there are records of 3,203 species, of which 694 occur in the Amazon Region (Brescovit et al., 2011). Within this group, we focus here on the Ctenidae family, a group which has received increasing attention due to their value as bioindicators of environmental quality, and the use of their venom neurotoxins as therapeutic agents (Rego et al., 2005; Mestre and Gasnier, 2008; Pinheiro et al., 2009).

More than 868 species of spiders have already been characterized cytogenetically and, of these, 12 belong to the family Ctenidae (Araujo et al., 2020). The data for this family show a diploid number varying between 22 and 29 chromosomes for males, and $\mathrm{X}_{1} \mathrm{X}_{2} 0$ and $\mathrm{X}_{1} \mathrm{X}_{2} \mathrm{X}_{3} 0$ sex chromosome systems (Araujo et al., 2014). While these two systems are rare overall, they are common in spiders (Araujo et al., 2012), including the Ctenidae, making it possible, in this Family, to study the sex chromosome behavior during meiosis.

In Ctenidae, with the exception of Asthenoctenus borellii Simon, 1897, whose diploid number is 22, all species have 26 autosomal chromosomes plus two or three sex chromosomes (Araujo et al., 2020). Araujo et al. (2014) sug-

Send correspondence to Eliana Feldberg. Instituto Nacional de Pesquisas da Amazônia, Programa de Pós-graduação em Genética, Conservação e Biologia Evolutiva, Avenida André Araújo, 2936, Petrópolis, 69.067-375, Manaus, AM, Brasil. E-mail: feldberg@inpa.gov.br. gest that the conversion of the sexual chromosomal system $\mathrm{X}_{1} \mathrm{X}_{2} 0$ to $\mathrm{X}_{1} \mathrm{X}_{2} \mathrm{X}_{3} 0$, and vice-versa, is a relatively common event. However, available cytogenetic data are currently insufficient to allow inferences concerning evolutionary chromosomal tendencies within the group.

The aim of the current study is to increase the cytogenetic knowledge of the Ctenidae, and so contribute to the discussion concerning mechanisms of chromosome evolution in this family, especially regarding the behavior of sexual chromosomal systems $\mathrm{X}_{1} \mathrm{X}_{2} 0$ and $\mathrm{X}_{1} \mathrm{X}_{2} \mathrm{X}_{3} 0$, in males during meiosis.

A total of 10 individuals (5 males of Ctenus amphora and 5 males of $C$. crulsi) were collected in a forest fragment surrounding the Federal University of Amazonas (UFAM), in the eastern part of the city of Manaus $\left(03^{\circ} 04^{\prime} 34\right.$ "S, $59^{\circ} 57^{\prime} 30^{\prime \prime} \mathrm{W}$ ), and 16 individuals (6 males of $C$. amphora, 8 males of $C$. crulsi, and 2 males of $C$. villasboasi) in the Adolpho Ducke Forest Reserve (2॰57’42"S, 5955'40"W) (Figure 1). In order to identify species of Ctenus we used Hofer et al. (1994). Collections were carried out under SISBIO license number 60728-1. Chromosomal preparation of male gonads was conducted according to Araujo et al. (2008). Fluorescent in situ hybridization (FISH) was performed following Pinkel et al. (1986), using 18S rDNA probes (Almeida et al., 2010), that showed 91\% homology with probes generated by Rincão et al. (2017) for Ctenus ornatus, and 92\% homology for Ctenus crulsi. The sequences were compared in BLASTN, using the National 


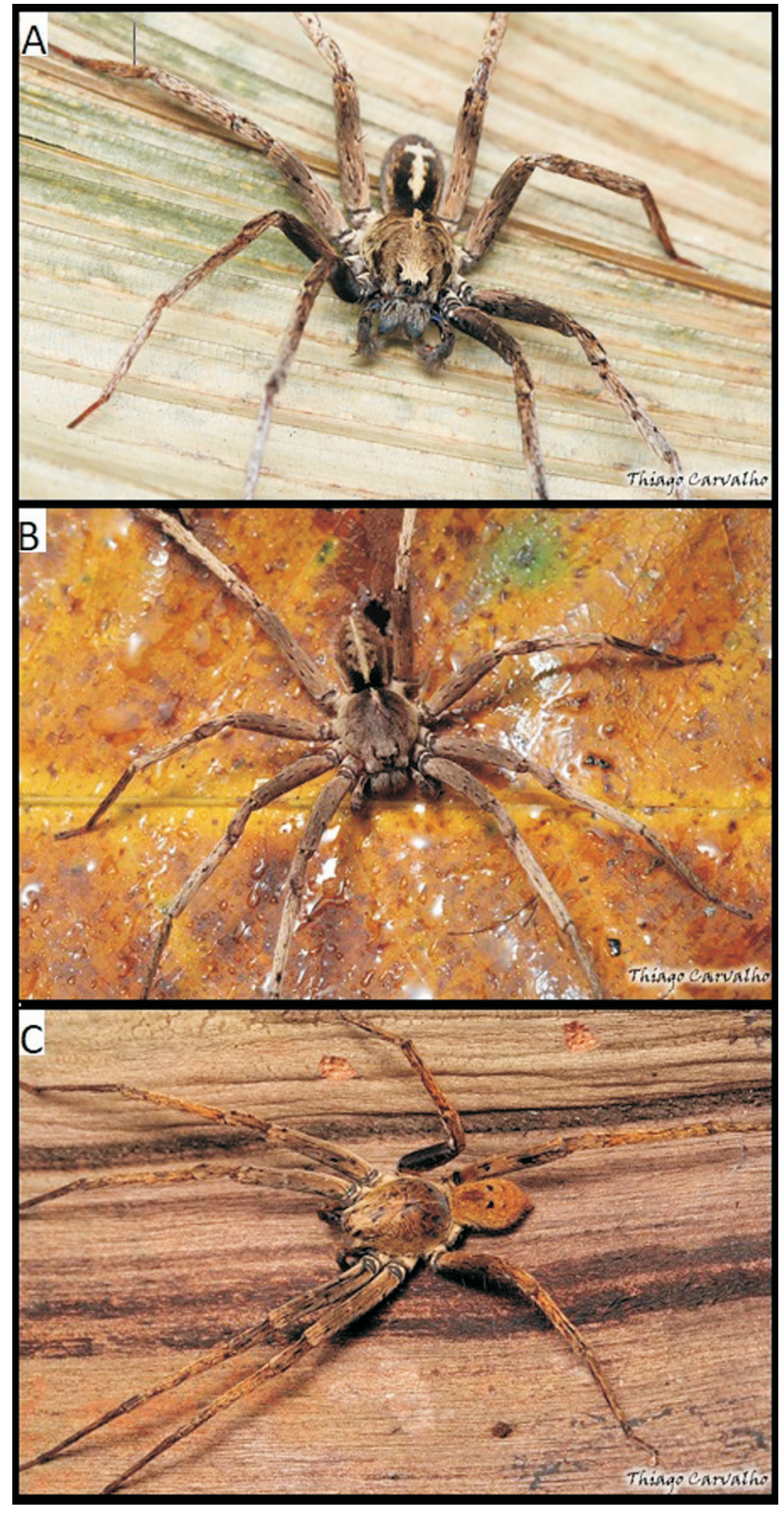

Figure 1 - Spiders species analyzed in the present study: (A) Ctenus amphora and its specific orange spot in the form of an inverted amphore; (B) Ctenus crulsi showing four medium black spots on the abdomen with black antero-lateral borders; (C) Ctenus villasboasi easily recognized by the coloration and ventral white marks on the coxae and on the apex of the sternum. Photos were taken by Thiago Gomes de Carvalho.

Center for Biotechnology Information (NCBI) database website (https://blast.ncbi.nlm.nih.gov/Blast.cgi). For Cbanding the Sumner (1972) protocol was followed. For AgNOR the Howell and Black (1980) protocol was followed.

In C. amphora (Figure 2A), C. crulsi (Figure 2B) and C. villasboasi (Figure $2 \mathrm{C}$ ) $2 \mathrm{n}=28$, with 26 of the chromosomes being autosomal and two sexual. In pachytene (Figure 3A, D, G) and dipotene (Figure 3B, E, H) phase cells the sex chromosomes showed positive heteropicnosis, thus allowing their identification. Determination of the sex chromosomal system was performed by analyzing chromosome segrega- tion during metaphase II of meiosis (Figure 3C, F, I), which shows nuclei with $\mathrm{n}=13$ and $\mathrm{n}=15\left(13+\mathrm{X}_{1} \mathrm{X}_{2}\right)$.

The FISH technique revealed 18S rDNA sites on pair 10 of the chromosomes in the spermatogonial metaphase of C. amphora and C. crulsi (Figure 2A, B). In addition, a $C$. crulsi individual from the Ducke Reserve was polymorphic compared to the other seven analyzed for this same locus, with four labeled chromosomes (Pairs 4 and 7) in spermatogonial metaphases (Figure 2B - highlighted). Ctenus villasboasi showed marking on a pair of chromosomes in metaphase (Figure 2C). However, chromosomal size visualized with this technique was insufficient to allow determination of which pair carried the 18S rDNA site.

C-banding showed the presence of constitutive heterochromatin in the centromeric region of all chromosomes, characterizing the morphology as acrocentric for all three species (Figure 4A-C). Silver nitrate impregnation revealed NORs on pair 10 in the spermatogonial metaphases for $C$. amphora and C. crulsi (most individuals) (Figure 2A, B). C. villasboasi had no visible markings in the spermatogonial metaphases, but exhibited marking on one pachytene bivalent (Figure 4D).

The karyotypic formula of males $\left(2 n=28-26+X_{1} X_{2} 0\right)$, found for all species, has been shown to be conserved in Ctenus (Araujo et al., 2020). Identification of sexual chromosomes in meiotic cells was facilitated by their high degree of condensation and positive heteropicnosis. The literature contains contrasting opinions regarding Ctenidae chromosomal morphology, with Araujo et al. (2014) considering them to be telocentric, while Kumar et al. (2017) and Rincão et al. (2017) consider that they are acrocentric. We considered the three species studied here to be acrocentric, based on C-banding, which showed markings in the centromeric regions of all chromosomes.

All three species showed metaphase II meiotic cells with $n=13$ and $n=15\left(13+X_{1} X_{2}\right)$, which agrees with the information given by Araujo et al. (2014) and Rincão et al. (2017) for Ctenidae species. This feature is common for a $\mathrm{X}_{1} \mathrm{X}_{2} 0$ sex chromosomal system, in which for males, at the end of meiosis I, two sex chromosomes migrate to the same pole cell.

Araújo et al. (2012) collated proposed spider chromosomal evolution theories, which include the $\mathrm{X} 0$ sexual chromosomal system giving rise to the $\mathrm{X}_{1} \mathrm{X}_{2} 0$ (White, 1940; Pätau, 1948), via part of an $X$ chromosome fissioning and attaching to a supernumerary chromosome (Bole-Gowda, 1950 ), and the sexual chromosomal system $X_{1} X_{2} X_{3} 0$ giving rise to $X_{1} X_{2} 0$ via fusion of two $X$ chromosomes (Král, 2007).

Taking into account the cytogenetic characterization of species considered basal within the Ctenidae, such as Nothroctenus sp. and Viracucha andicola Simon, 1906 (Polotow and Brescovit, 2014), and the data presented here for Ctenidae species occuping positions considered to be derived, we believe the diploid number reduction hypotheses based on chromosome fusion to be more parsimonious, since the first group has $2 \mathrm{n}=29$ and the second group has $2 \mathrm{n}=28$. 


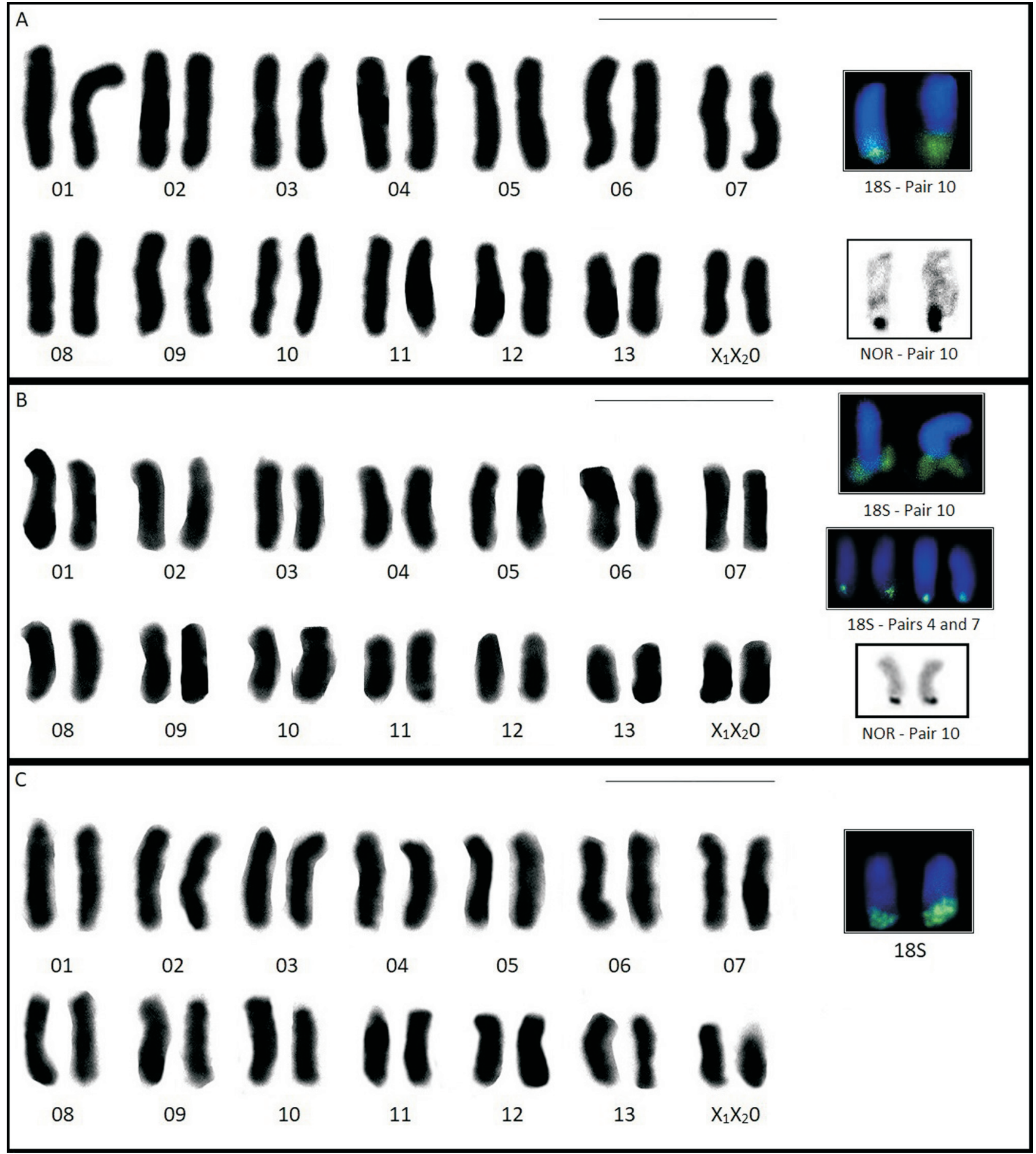

Figure 2 - Karyotypes of the studied species: (A) Ctenus amphora; (B) C. crulsi and (C) C. villasboasi showing nucleolar pair marked by silver nitrate impregnation and FISH with $18 \mathrm{~S}$ rDNA (Green marks). Scale $=10 \mu \mathrm{m}$. One C. crulsi individual from the Ducke Reserve presented four labeled chromosomes (pairs 4 and 7) (Figure 1B - highlighted).

However, Rincão et al. (2020) recently found two individuals of $C$. ornatus showing one supernumerary chromosome and one individual with two supernumerary chromosomes. Those chromosomes showed positive heteropicnosis and behavior similar to sex chromosomes, which the author states may demonstrate conversion of sexual chromosomal system $\mathrm{X}_{1} \mathrm{X}_{2} 0$ to $\mathrm{X}_{1} \mathrm{X}_{2} \mathrm{X}_{3} \mathrm{X}_{4} 0$ for the first time in Ctenidae.
The FISH-obtained 18S rDNA tags for the three species in our study confirmed Ag-NOR derived data, and were similar to those described for $C$. ornatus and $C$. medius by Rincão et al. (2017). However, an individual of C. crulsi in the current study had two pairs of chromosomes with $18 \mathrm{~S}$ rDNA labeling (Pairs 4 and 7). These additional markers were shown to be relatively minor when compared to that 


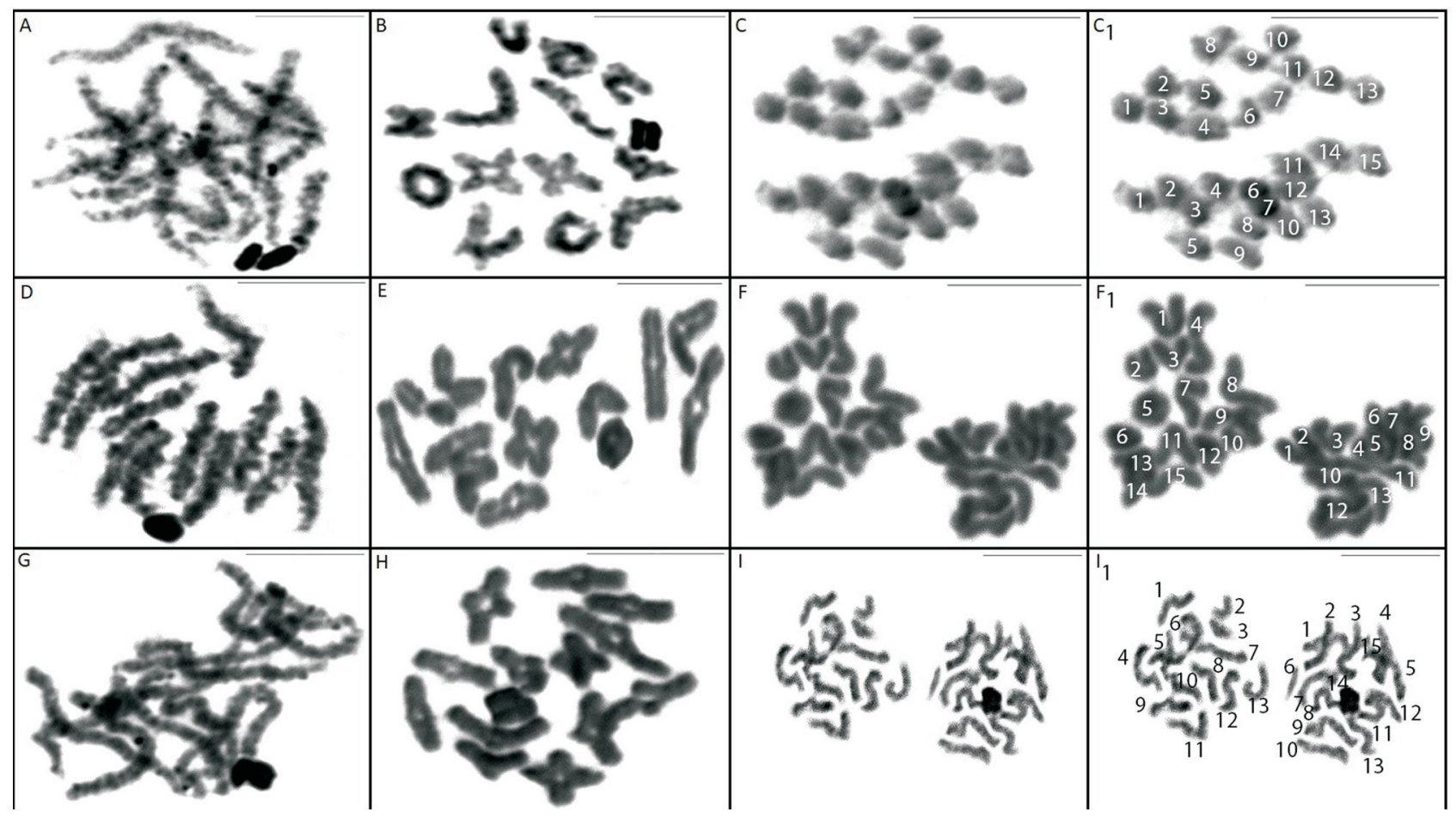

Figure 3 - Meiotic cells in pachytene (A, D, G), diplotene (B, E, H) and metaphase II (C, F, I) of: Ctenus amphora. (A, B, C); C. crulsi. (D, E, F); C. villasboasi $(\mathrm{G}, \mathrm{H}, \mathrm{I})$. Metaphase II cells shows the division of chromosome between cells poles, with $\mathrm{n}=13$ and $\mathrm{n}=15\left(13+\mathrm{X}_{1} \mathrm{X}_{2}\right)$ during segregation. Scale $=10 \mu \mathrm{m}$.

found in the other Ctenus species of the current study, as well as those available in the literature. Such data suggest that these alterations can be caused by chromosomal rearrangements, insertions by transposable elements or ectopic recombination, all processes that could, potentially, be involved in karyotypic differentiation and new species emergence (Stáhlavsky et al., 2018).

Considering the number of chromosomes with $18 \mathrm{~S}$ rDNA in C. crulsi, we believe the translocation hypothesis to be the most feasible, since this mechanism of chromosome evolution depends on the interchange of segments between two non-homologous chromosomes without loss of genetic material (Gross et al., 2010). Such translocations can be simple, when only the segment of one chromosome passes to the other, or reciprocal, when two chromosomes exchange segments with each other. The translocation model for rDNA is described by Araujo et al. (2015) for the exchange of such segments between autosomal and sexual chromosomes in the genus Nephila. This shows that a possible translocation between the two types of chromosomes is possible. In the $C$. crulsi metaphases analyzed here, the sex chromosomes were not evident.

Silver nitrate impregnation showed NOR markers on an autosomal pair for $C$. amphora and C. crulsi (most individuals), and on a pachytene bivalent for $C$. villasboasi, a result similar to that found for C. ornatus Keyserling, 1877 (Araujo et al., 2014; Rincão et al., 2020), and C. medius (Rincão et al., 2020), but which differs from those reported for C. indicus Gravely, 1931, by Kumar et al. (2017), and for
G. longipes by Rincão et al. (2020), who found NOR markings on two chromosome pairs. The NOR distribution pattern is currently known for only five species in the genus Ctenus. Therefore, we suggest that additional cytogenetic studies are still needed to establish the plesiomorphic characteristics of the Ctenidae karyotype and, thus, to be able to understand the mechanisms of chromosomal evolution that occurred in this group of spiders.

The pattern of constitutive heterochromatin distribution reported here for C. amphora, C. crulsi and C. villasboasi is similar to those found by Rincão et al. (2017) for $C$. medius Keyserling, 1891, E. cyclothorax Bertkau, 1880, $P$. nigriventer Keyserling, 1891 and $V$. andicola, with blocks in the centromeric regions of all the chromosomes.

According to Sumner (1972), C-banding marks centromeric and telomeric regions, possibly marking nucleolar regions and, rarely, intercalated regions of the chromosome. In the metaphases studied here, the sex chromosomes were not totally heterochromatic, thus confirming heteropycnosis of the sex chromosomes in meiosis. Heterochromatic chromosomes remain condensed throughout the cell cycle, whereas heteropycnotic chromosomes may have a higher or lower level of condensation, depending on the stage of cell division in which they are found (John, 1990).

As a result of the current study, the number of Ctenidae species with chromosomal data has been increased to 14 . The data obtained for C. amphora, C. crulsi and C. villasboasi extends to seven the number of species analyzed from the genus Ctenus, and so allow a conserved karyotype to be 


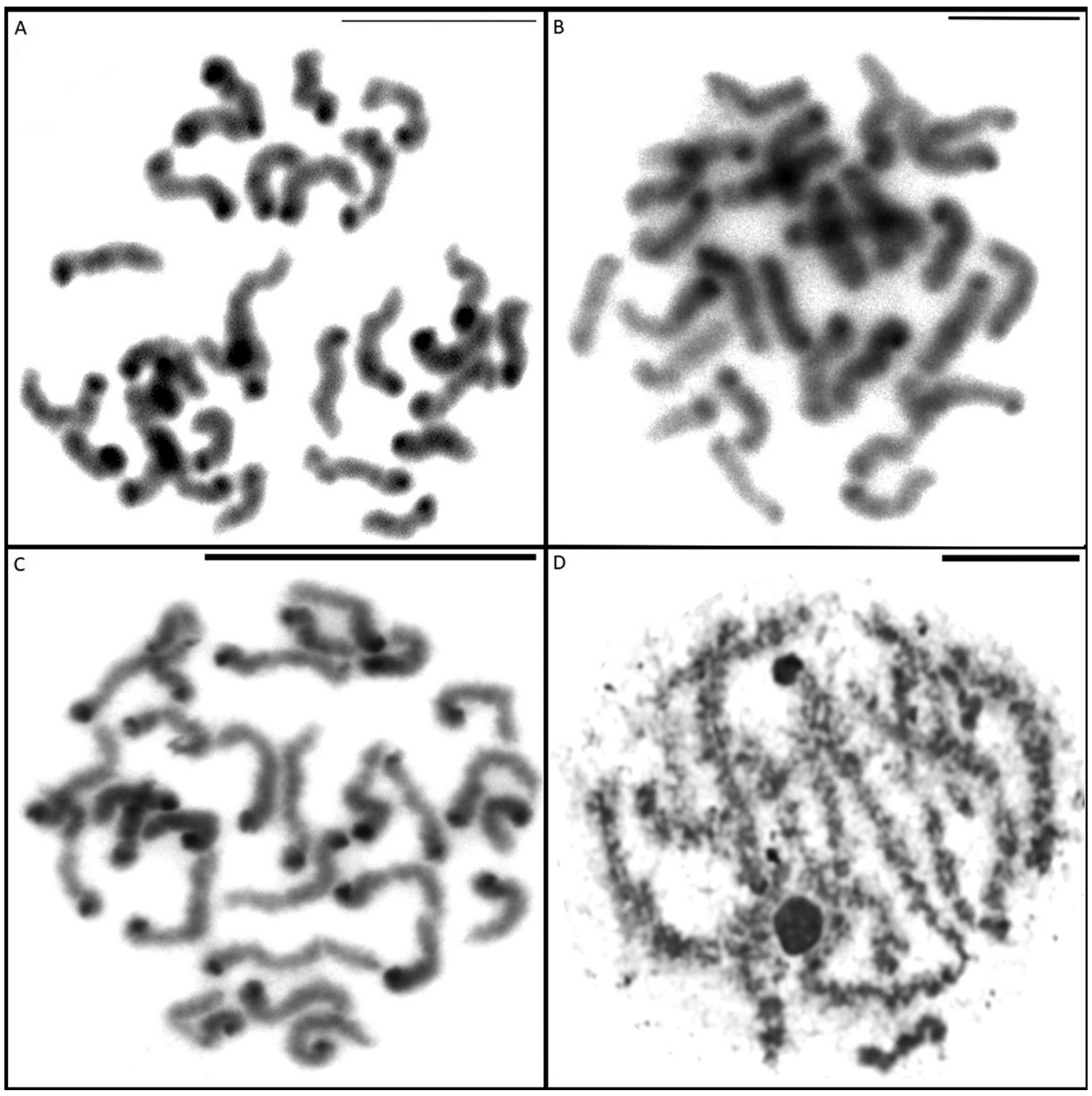

Figure 4 - Mitotic cells submitted to C-banding (A, B e C) and silver nitrate impregnation (D). (A) C. amphora, (B) C. crulsi and (C) C. villasboasi showing heterochromatin in the centromeric region of chromosomes. (D) C. villasboasi showing NORs in pachytene bivalent. Scale $=10 \mu \mathrm{m}$.

infered, as well as the diploid number, chromosomal formula and sex chromosome system plus mapping of the rDNA sites, constitutive of sex chromosomes in meiotic cells in pachytene and diplotene phases is a common feature for these species (Araújo et al., 2012). The results also reinforce theories of chromosome fusion as a possible evolutionary tendency in this family.

\section{Acknowledgments}

This research was supported by Conselho Nacional de Desenvolvimento Científico e Tecnológico, CNPq (131774/2016-6). Collection permits were granted by Instituto Chico Mendes de Conservação e Biodiversidade (ICMBio; 60728-1). The authors also thank the researcher Dra. Marielle Schneider for helping to obtain the spider chromosomes and Thiago Gomes de Carvalho for giving us the pictures of the spiders. Dr. Adrian A. Barnett reviewed the English.

\section{Conflict of Interest}

The authors declare that there is no conflict of interest that could be perceived as prejudicial to the impartiality of the reported research.

\section{Author Contributions}

JPCPN, LGG, MCG and CHS conceived the study; JPCPN and LGG collected the individuals and conducted the experiments; JPCPN, LGG, MCG, EF and CHS analyzed the data; JPCPN, LGG, EF, MCG and CHS wrote the manuscript. All authors read and approved the final version. 


\section{References}

Almeida MC, Goll LG, Artoni RF, Nogaroto V, Matiello RR and Vicari MR (2010) Physical mapping of 18S rDNA cistron in species of the Omophoita genus (Coleoptera, Alticinae) using fluorescent in situ hybridization. Micron 41:729-734.

Araujo D, Rheims CA, Brescovit AD and Cella DM (2008) Extreme degree of chromosome number variability in species of the spider genus Scytodes (Aranae, Haplogynae, Scytodidae). J Zool Syst Evol Res 46:89-95.

Araujo D, Oliveira EG, Giroti AM, Mattos VF, Paula-Neto E, Brescovit AD, Schneider MC and Cella DM (2014) Comparative cytogenetics of seven Ctenidae species (Araneae). Zool Sci 31:83-88.

Araujo D, Oliveira EG, Giroti AM, Mattos VF, Paula-Neto E, Brescovit AD, Schneider MC and Cella DM (2015) Chromosome evolution in lycosoid spiders (Araneomorphae): a scenario based on analysis of seven species of the families Lycosidae, Senoculidae and Trechaleidae. J Arachnol 43:174-181.

Bole-Gowda BN (1950) The chromosome study in the spermatogenesis of two lynx-spiders (Oxyopidae). Proc Zool Soc Bengal 2:95-107.

Brescovit AD, Oliveira U and Santos AJ (2011) Spiders (Araneae, Arachnida) from São Paulo State, Brazil: diversity, sampling efforts, and state-of-art. Biota Neotrop 11:717-747.

Gross MC, Schneider CH, Valente GT, Martins C and Feldberg E (2010) Variability of 18S rDNA locus among Symphysodon fishes: chromosomal rearrangements. J Fish Biol 76:1117-1127.

Hofer H, Brescovit AD and Gasnier T (1994) The wandering spiders of the genus Ctenus (Ctenidae, Araneae) of reserva Ducke, a rainforest reserve em central Amazonia. Andrias, 13:81-98.

Howell WM and Black DA (1980) Controlled silver-staining of nucleolus organizer regions with a protective colloidal developer: a 1- step method. Experientia 36:1014-1015.

John B (1990) Meiosis. Cambridge University Press, Cambridge, $396 \mathrm{p}$.

Král J (2007) Evolution of multiple sex chromosomes in the spider genus Malthonica (Araneae: Agelenidae) indicates unique structure of the spider sex chromosome systems. Chromosome Res 15:863-879.

Kumar SA, Venu G, Jayaprakash G and Venkatachalaiah G (2017) Studies on chromosomal characteristics of Ctenus indicus (Gravely 1931) (Araneae: Ctenidae). Nucleus 60:17-23.

Mestre LAM and Gasnier TRJ (2008) Populações de aranhas errantes do gênero Ctenus em fragmentos florestais na Amazônia Central. Acta Amaz 38:159-164.

Pätau K (1948) X-segregation and heterochromasy in the spider Aranea reaumuri. Heredity 2:77-100.
Pinheiro ACN, Silva AJ, Prado MAM, Cordeiro MN, Ricardson M, Batista MC, Massensini AR, Fonseca CG, Silva MAR, Kushmerick C et al. (2009) Phoneutria spider toxins block ischemia-induced glutamate release, neuronal death, and loss of neurotransmission in hippocampus. Hippocampus 19:1123-1129.

Pinkel D, Straume T and Gray JW (1986) Cytogenetic analysis using quantitative, high sensitivity, fluorescence hybridization. Proc Natl Acad Sci USA 83:2934-2938.

Polotow D and Brescovit, AD (2014) Phylogenetic analysis of the tropical wolf spider subfamily Cteninae (Arachnida, Araneae, Ctenidae). Zool J Linnean Soc 170:333-361.

Rego FNAA, Venticinque EM and Brescovit AD (2005) Densidade de aranhas errantes (Ctenidae e Sparassidae, Araneae) em uma floresta fragmentada. Biota Neotrop 5(1A):45-52.

Rincão MP, Chavari JL, Brescovit AD and Dias AL (2017) Cytogenetic analyses of five Ctenidae species (Araneae): detection of heterochromatin and $18 \mathrm{~S}$ rDNA sites. Comp Cytogenet 11:627-639.

Rincão MP, Brescovit AD and Dias AL (2020) Insights on repetitive DNA behavior in two species of Ctenus Walckenaer, 1805 and Guasuctenus Polotow and Brescovit, 2019 (Araneae, Ctenidae): evolutionary profile of $\mathrm{H} 3$ histone, $18 \mathrm{~S}$ rRNA genes and heterochromatin distribution. PLoS ONE 15:e0231324.

Stáhlavsky F, Opatova V, Just P, Lotz LN and Haddad CR (2018) Molecular technique reveals high variability of $18 \mathrm{~S}$ rDNA distribution in harvestmen (Opiliones, Phalangiidae) from South Africa. Comp Cytogenet 12:41-59.

Sumner AT (1972) A simple technique for demonstrating centromeric heterochromatin. Exp Cell Res 75:304-306.

White MJD (1940) The origin and evolution of multiple sexchromosome mechanisms. J Genet 40:303-336.

\section{Internet Resources Section}

Araújo D, Schneider MC, Paula-Neto E and Cella DM (2012) Sex Chromosomes and Meiosis in Spiders: A review. Meiosis Molecular Mechanisms and Cytogenetic Diversity, Andrew Swan, IntechOpen, https://www.intechopen.com/books/meiosis-molecular-mechanisms-and-cytogenetic-diversity/sex-ch romosomes-and-meiosis-of-spiders-a-review.

Araujo D, Schneider MC, Paula-Neto E and Cella DM (2020) The spider cytogenetic database, www.arthropodacytogenetics.bio.br/spiderdatabase.

World Spider Catalog, Version 21.0, https://wsc.nmbe.ch.

Associate Editor: Dr. Maria Jose de Jesus Silva

License information: This is an open-access article distributed under the terms of the Creative Commons Attribution License (type CC-BY), which permits unrestricted use, distribution and reproduction in any medium, provided the original article is properly cited. 